\title{
Differential Effects of Cocaine on Dopamine Neuron Firing in Awake and Anesthetized Rats
}

\author{
Stanislav Koulchitsky ${ }^{1,4}$, Benjamin De Backer ${ }^{2,4}$, Etienne Quertemont ${ }^{3}$, Corinne Charlier ${ }^{2}$ and \\ Vincent Seutin*,' \\ 'Laboratory of Pharmacology and GIGA Neurosciences, University of Liège, Sart Tilman/Liège, Belgium; 'Laboratory of Clinical, Forensic, \\ Environmental and Industrial Toxicology, CIRM, CHU Sart-Tilman, University of Liège, Sart Tilman/Liège, Belgium; ${ }^{3}$ Department of Cognitive \\ Sciences, University of Liège, Sart Tilman/Liège, Belgium
}

\begin{abstract}
Cocaine (benzoylmethylecgonine), a natural alkaloid, is a powerful psychostimulant and a highly addictive drug. Unfortunately, the relationships between its behavioral and electrophysiological effects are not clear. We investigated the effects of cocaine on the firing of midbrain dopaminergic (DA) neurons, both in anesthetized and awake rats, using pre-implanted multielectrode arrays and a recently developed telemetric recording system. In anesthetized animals, cocaine ( $10 \mathrm{mg} / \mathrm{kg}$, intraperitoneally) produced a general decrease of the firing rate and bursting of DA neurons, sometimes preceded by a transient increase in both parameters, as previously reported by others. In awake rats, however, injection of cocaine led to a very different pattern of changes in firing. A decrease in firing rate and bursting was observed in only $14 \%$ of DA neurons. Most of the other DA neurons underwent increases in firing rate and bursting: these changes were correlated with locomotor activity in $52 \%$ of the neurons, but were uncorrelated in $29 \%$ of them. Drug concentration measurements indicated that the observed differences between the two conditions did not have a pharmacokinetic origin. Taken together, our results demonstrate that cocaine injection differentially affects the electrical activity of DA neurons in awake and anesthetized states. The observed increases in neuronal activity may in part reflect the cocaine-induced synaptic potentiation found ex vivo in these neurons. Our observations also show that electrophysiological recordings in awake animals can uncover drug effects, which are masked by general anesthesia.
\end{abstract}

Neuropsychopharmacology (2012) 37, 1559-157|; doi:I0.1038/npp.20 I.339; published online I February 2012

Keywords: dopamine neurons; telemetric recording; cocaine; electrophysiology

\section{INTRODUCTION}

Cocaine (benzoylmethylecgonine) is a naturally occurring alkaloid extracted from plants belonging to the Erythroxylum species. It is known to produce a number of pharmacological effects, including psychomotor stimulation, hypertension, tachycardia, anorexia, and pupillary dilation. Central effects of cocaine are attributed to its ability to inhibit reuptake of dopamine, serotonin, and norepinephrine (Reith et al, 1986, 1997b; Richelson and Pfenning, 1984; Ritz et al, 1990; Ross and Renyi, 1967). It is believed that blockade of the uptake, by increasing the synaptic concentrations of these neurotransmitters (Bradberry and Roth, 1989; Li et al, 1996; Reith et al, 1997a), leads to an

\footnotetext{
*Correspondence: Professor $\vee$ Seutin, Laboratory of Pharmacology and GIGA Neurosciences, University of Liège (B36), B-4000 SartTilman/Liège I, Belgium, Tel: + 32 43662525, Fax: + 32 43662523, E-mail: V.Seutin@ulg.ac.be

${ }^{4}$ These two authors contributed equally to this work.

Received 3 November 201 I; accepted 22 December 201 I
}

increase in vigilance and sensory awareness, activation of defense mechanisms, cognitive distortion, euphoria, and a reduced need for sleep (Clark et al, 1985b; Freye and Levy, 2009).

Owing to its potent rewarding effect, cocaine has a high abuse liability. Its consumption in modern society has become increasingly common, as shown by population statistics (Clark et al, 1985b; Freye and Levy, 2009). Consequences of chronic use include a massive addiction, an increased risk of psychiatric illnesses, and deleterious consequences on general health (eg, an increased risk of myocardial infarction) (Lange and Hillis, 2001).

The addictive properties of cocaine are thought to be mediated mainly by the dopaminergic (DA) mesocorticolimbic system - the pathways projecting from the ventral tegmental area (VTA) to the medial prefrontal cortex, nucleus accumbens (NAc), amygdala, and hippocampus (Chiodo et al, 1984; McCutcheon et al, 2009; Peoples et al, 1998; Wise and Bozarth, 1984). Using in vivo voltammetry, it was shown that systemic cocaine injection in awake and behaving rats produces a significant increase of DA 
concentration in NAc synapses, correlating to the cocaineinduced psychostimulant behaviors (Broderick et al, 1993). On the other hand, application of cocaine in electrophysiological experiments leads to a decrease in the firing of DA neurons in vivo (Einhorn et al, 1988; Hinerth et al, 2000; Mercuri et al, 1992) and a hyperpolarization of DA neurons in vitro (Brodie and Dunwiddie, 1990; Einhorn et al, 1988; Lacey et al, 1990; Mercuri et al, 1991, 1992). These effects are explained by the fact that dopamine, released from the axons and dendrites, enhances the activity of an NAc-VTA GABAergic negative feedback and activates somatodendritic autoreceptors on the DA neurons (Einhorn et al, 1988; Kalivas, 1993; Wang, 1981; White and Wang, 1984a, b, 1986). However, in vivo electrophysiological experiments mentioned above were conducted under general anesthesia, which is known to change the responses of central neurons to various compounds (Kelland et al, 1990, 1989; Nicoll and Madison, 1982; Windels and Kiyatkin, 2006). In particular, it was shown that anesthesia affects cocaine metabolism (Benuck et al, 1989; Pan et al, 1995), alters the reactivity of DA neurons to glutamate, GABA, DA agonists, and DA antagonists (Bunney et al, 1973a; Clark et al, 1985a, b; Gessa et al, 1985; Kelland et al, 1990, 1989; Melis et al, 1998; Mereu et al, 1984, 1987; Windels and Kiyatkin, 2006), and interferes with DA turnover (Westerink et al, 1977). For example, nicotine and ethanol have a stimulating effect on the VTA neurons in awake rats, but fail to activate them in anesthetized animals (Gessa et al, 1985; Mereu et al, 1987). A number of combined electrophysiological and behavioral studies on cocaine have been performed in awake rats, but have mostly focused on NAc neurons (Carelli, 2002; Carelli and Deadwyler, 1994; Peoples et al, 1998; Peoples and West, 1996; Stuber et al, 2005).

On the other hand, in vitro investigations of the cocaine effect on VTA neurons were performed in slices, where some important regulatory pathways are severed. These caveats make it difficult to compare cocaine-induced electrophysiological effects in the midbrain and its behavioral actions. Thus, the question of how cocaine administration changes the activity of DA neurons in awake, behaving animals remains open.

To address this issue, we measured the effects of this drug on the firing rate and pattern of midbrain DA neurons in both awake (and freely moving) and anesthetized rats, taking advantage of the recent development of telemetric techniques. In addition, we measured plasma and brain concentrations of cocaine and its main metabolite, benzoylecgonine (BZE) (Freye and Levy, 2009), in order to evaluate the possibility of differential pharmacokinetics of cocaine in the two conditions and to measure the actual brain concentrations after the injection of a behaviorally relevant dose of the drug.

\section{MATERIALS AND METHODS}

\section{Subjects}

Adult male Wistar rats, weighing $290-310 \mathrm{~g}$ at the time of surgery, were housed individually and maintained on a 12-h light: 12 -h dark cycle. Water and food were available $a d$ lib. All animal care and handling was conducted in accordance with the guidelines stated in the Handbook for the Use of
Animals in Neuroscience Research (Society for Neuroscience, 1991). All procedures were carried out in accordance with guidelines of the European Communities Council Directive of 24 November 1986 (86/609/EE) and were approved by the Ethics Committee for Animal Use of the University of Liege (protocol 86).

\section{Surgical and Histological Procedures}

Rats were anesthetized with chloral hydrate $(400 \mathrm{mg} / \mathrm{kg}$, intraperitoneally (i.p.)), and placed in a stereotaxic apparatus (Model 902, Kopf). Soft tissues of the skull were anesthetized using a subcutaneous injection of $0.5 \%$ lidocaine hydrochloride. Additional supplemental doses of chloral hydrate and/or lidocaine were injected when necessary. Body temperature was maintained at $36-37^{\circ} \mathrm{C}$ by means of a heating pad. The skin was retracted, and the exposed bone cleaned with saline and a 3\% hydrogen peroxide solution. Four to five small holes were made in the skull around the area of entry using a $1.10 \mathrm{~mm}$ diameter dental burr (Microtorque II control box, Tech 2000 Handpiece, Ram Products, Encino, CA), and small stainless-steel screws $\left(1.20 \times 3.15 \mathrm{~mm}^{2}\right)$ were screwed to subsequently anchor the microelectrode array (MEA) to the skull using dental restorative material.

The area of entry was defined according to stereotaxic coordinates (Ford and Williams, 2008). A small part of the skull between the lambda and the bregma was removed above the implantation point using a $0.4 \mathrm{~mm}$ diameter dental burr. An MEA (8 recording and one reference electrode; Supplementary Figure S1) was mounted on the micromanipulator and the tips of the electrodes were lowered into the VTA through the opening $(5.8-6.8 \mathrm{~mm}$ posterior to the bregma, $0.6-0.9 \mathrm{~mm}$ lateral to the midline, and 7.5-8.5 $\mathrm{mm}$ under the cortical surface; Supplementary Figures S1 and S2A). The MEA was fixed to the rat's skull and the supporting screws using Z100 dental restorative and Adper Scotchbond multi-purpose adhesive (3M ESPE Dental Products, St. Paul, MN). A scheme representing the geometry of the electrodes in the MEA is shown in Supplementary Figure S1B.

At the end of the recordings, the rats were deeply anesthetized and perfused intracardially with saline, followed by a $4 \%$ formaldehyde saline solution. The brains were removed and stored at $4{ }^{\circ} \mathrm{C}$ in a $4 \%$ formaldehyde/ sucrose solution. Frozen sections $(80 \mu \mathrm{m})$ were cut, mounted, and stained with cresyl violet for histological examination (Gold et al, 2006). In all experiments reported here, this examination confirmed that the recording electrodes were positioned within the dorsocaudal section of the VTA (Supplementary Figure S2A and B). According to tracing experiments, the caudal VTA contains a higher proportion of DA than GABAergic neurons and gives rise to more mesoaccumbal projections than does the rostral VTA (Swanson, 1982). This area is also known to be more important for the rewarding and addictive effects of drugs of abuse than the rostral VTA (Ikemoto, 2007; Krebs et al, 2011).

\section{Recording of Neuronal Activity}

Extracellular electrical activity was recorded using a newly developed wireless recording system (TeleSpike; Alpha 
Omega $\mathrm{GmbH}$, Israel). The transmitter was placed on the animal's back using a special jacket and was connected to the pre-implanted MEA via an Omnetics connector. The receiver was connected to the computer via a USB cable.

\section{Monitoring of Locomotor Activity}

During the experiment, animals were placed into $30 \times 43.2 \times 43.2 \mathrm{~cm}^{3}$ Plexiglas chambers. Their locomotor activity was monitored using an MED-OFA Activity Monitor (MED Associates, St. Albans, VT).

To habituate the animals to the experimental conditions, each of them was placed into the experimental chamber for 30 min 2 days before the surgery and for $1,2,3$, and $3.5 \mathrm{~h}$, respectively, during the 4 days after the surgery. Experiments were run 4-6 days after surgery.

\section{Experimental Protocols}

Non-anesthetized animals $\left(n_{\text {rats }}=23\right)$ were placed into the experimental chambers $30 \mathrm{~min}$ before the beginning of the protocol. The protocol consisted of four consecutive sessions, each $45 \mathrm{~min}$ long:

- Session 1: Electrical activity and behavior was recorded continuously.

- Session 2: At the beginning of the session, animals received an injection of saline $\left(0.5 \mathrm{ml}\right.$, i.p.; $\left.n_{\text {rats }}=23\right)$.

- Session 3: At the beginning of the session, animals received an injection of cocaine $(10 \mathrm{mg} / \mathrm{kg}$ in $0.5 \mathrm{ml}$ of saline, i.p.; $\left.n_{\text {rats }}=13\right)$ or saline $\left(0.5 \mathrm{ml}\right.$, i.p.; $\left.n_{\text {rats }}=10\right)$.

- Session 4: At the beginning of the session, animals received an injection of the D2/D3 agonist quinpirole $(100 \mu \mathrm{g} / \mathrm{kg}$, an autoreceptor-selective dose, in $0.5 \mathrm{ml}$ of saline, i.p.; $n_{\text {rats }}=23$ ).

Animals that were anesthetized with chloral hydrate ( $400 \mathrm{mg} / \mathrm{kg}$, supplemented as needed; $\left.n_{\text {rats }}=14\right)$ underwent the same experimental protocol. At the beginning of Session 3 , seven rats received an injection of cocaine $(10 \mathrm{mg} / \mathrm{kg}$ in $0.5 \mathrm{ml}$ of saline, i.p.) and the other seven rats received an injection of saline $(0.5 \mathrm{ml}$, i.p.).

The dose of $10 \mathrm{mg} / \mathrm{kg}$ cocaine is assumed to be a lowrange dose for the i.p. route of administration (Horger et al, 1999; O'Dell et al, 1996; Porrino, 1993). In addition, we performed the same experiments on awake $\left(n_{\text {rats }}=5\right)$ and anesthetized $\left(n_{\text {rats }}=5\right)$ rats, with a 10 times lower dose of cocaine ( $1 \mathrm{mg} / \mathrm{kg}$, i.p.).

\section{Identification of DA Neurons}

Electrophysiological and pharmacological parameters were used in order to identify DA neurons. In vivo, these neurons exhibit an irregular firing pattern with interspersed bursting episodes and long ( $>1.5 \mathrm{~ms})$, triphasic spikes, often displaying a prominent notch in the initial positive rising phase. They have a slow firing rate (range: $0.5-5 \mathrm{~Hz}$; Bunney et al, 1973b). In addition, we used a pharmacological control, namely an intraperitoneal injection of the D2/D3 agonist quinpirole $(100 \mu \mathrm{g} / \mathrm{kg})$, at the end of each experiment (see above: Session 4). This dose is supposed to predominantly activate D2/D3 autoreceptors (Li et al, 1996;
White and Wang, 1983), thereby inhibiting the firing of those DA neurons that have a high density of these receptors on the soma and dendrites, that is, most of midbrain DA neurons, except the mesoprefrontal ones (Chiodo et al, 1984; Ford and Williams, 2008; Lammel et al, 2008). Units that had broad spikes, a low firing rate, and exhibited a slowing (of at least $50 \%$ ) or a complete cessation of their firing after quinpirole injection were assumed to be 'non-mesoprefrontal' VTA DA neurons.

We did not use the spike shape as a criterion because the exact electrode position could not be controlled in our experimental conditions. Several studies have demonstrated that the extracellular spike waveform varies with the electrode position relatively to the site of action potential generation in the recorded cell (Berretta et al, 2010; Cohen and Miles, 2000; Gold et al, 2006).

\section{Data Analysis}

The fast transients corresponding to spontaneous action potentials were captured online using the Alpha Omega TeleSpike software, and were subsequently transferred to the Spike2 6.0 software (Cambridge Electronic Design, Cambridge, UK) and analyzed off-line by means of an amplitude threshold adjusted by visual inspection in each individual active channel. We also calculated the percentage of spikes generated in a burst firing pattern with regard to the total number of spikes. Bursts were identified using previously established criteria for discriminating burst from non-burst events in A10 and A9 DA neurons (Clark and Chiodo, 1988; Grace and Bunney, 1984). A spike train was considered to be a burst when it contained at least three successive spikes, with the onset defined as an interspike interval of $80 \mathrm{~ms}$ or less and burst termination as an interspike interval of $160 \mathrm{~ms}$ or greater.

\section{Pharmacokinetic Study}

For the pharmacokinetic study, experimental conditions were set as close as possible to those of the electrophysiological recordings. Awake rats $\left(n_{\text {rats }}=11\right)$ were placed into experimental boxes $30 \mathrm{~min}$ before the beginning of the protocol. Each of them then received an i.p. injection of cocaine $(10 \mathrm{mg} / \mathrm{kg}$ in $0.5 \mathrm{ml}$ of saline). Rats were killed 10 or 30 min after the injection ( $n_{\text {rats }}=5$ and 6 , respectively).

The other group of rats $\left(n_{\text {rats }}=12\right)$ was anesthetized with an intraperitoneal injection of chloral hydrate $(400 \mathrm{mg} / \mathrm{kg})$. About $15 \mathrm{~min}$ after the animals were injected, they received an injection of cocaine $(10 \mathrm{mg} / \mathrm{kg}$ in $0.5 \mathrm{ml}$ of saline, i.p.), and were killed 10 or 30 min afterwards $\left(n_{\text {rats }}=6\right.$ and 6 , respectively).

Sampling procedures were adapted from Bowman et al (1999). Animals were killed by decapitation. Brain tissue and blood collected from trunk vessels were used to measure cocaine and BZE levels (see Supplementary materials for details).

\section{Drugs and Chemicals}

Cocaine hydrochloride for i.p. injection was obtained from Fagron (Waregem, Belgium). Heparin was from LEO Pharma (Lier, Belgium). Quinpirole was obtained from 
Tocris (Bristol, UK). All LC-MS grade solvents were purchased from Biosolve (Valkenswaard, The Netherlands) and other chemicals were from Sigma (Steinheim, Germany).

Cocaine and BZE reference materials and internal standards were purchased from LGC Promochem (Molsheim, France). All standards had a degree of purity $>99 \%$.

\section{Statistical Analysis}

All values are presented as means \pm SEM. Comparison of the main groups was performed by a hierarchical analysis of variance (ANOVA) using $1 \mathrm{~min}$ periods for single data points (bin size). The neurons were nested within the rats, which were in turn nested within the treatment groups (anesthetized $v s$ non-anesthetized subjects). The treatment groups were treated as a between-subject factor, while time points before and after cocaine administration were treated as a within-subject factor. Changes in neuronal activity within each group were analyzed using $5 \mathrm{~min}$ bins compared with the last or next to last period before infusion (ANOVA for repeated measures followed by Dunnett's post hoc test). Statistical significance was set at $p<0.05$.

Cocaine and BZE plasma and brain concentrations were evaluated by a two-tailed Student's $t$-test.

\section{RESULTS}

\section{Behavioral Effects of Cocaine $(10 \mathrm{mg} / \mathrm{kg}$, i.p.) and Saline Injections}

Injection of $10 \mathrm{mg} / \mathrm{kg}$ i.p. cocaine at the beginning of Session $3\left(n_{\text {rats }}=13\right)$ was followed by a variable increase in locomotor activity and stereotypic movement over $45 \mathrm{~min}$. The animals were divided into two groups: low cocaine responders (LCRs, $n_{\text {rats }}=6$ ) and high cocaine responders (HCRs, $n_{\text {rats }}=7$ ), using the method of Sabeti et al (2002). Briefly, the distance traveled by all the animals over the first 30 min was measured and the values were ranked. Animals whose values were below and equal to or above the median were defined as LCRs and HCRs, respectively (see Supplementary Figure S3).

Injection of saline at the beginning of Session 2 $\left(n_{\text {rats }}=23\right)$ and at the beginning of Session $3\left(n_{\text {rats }}=10\right)$ provoked only a short-term increase in locomotor activity, which lasted for $\sim 5 \mathrm{~min}$.

Analysis of locomotor behavior during the baseline period did not reveal significant differences between the LCR and HCR groups.

\section{Characteristics of Recorded Neurons}

Recordings were made from a total of 134 units in 28 awake rats and a total of 94 units in 19 anesthetized rats. Using the criteria described in the Materials and methods, we classified 107 units in 24 awake animals and 80 units in 19 anesthetized animals as presumably DA. These units had broad spikes $(>1.5 \mathrm{~ms})$ and a slow irregular firing, with intermittent periods of bursts. Their average firing frequency during the baseline period was $1.28 \pm 0.21 \mathrm{~Hz}$ with $14.3 \pm 5.8 \%$ of spikes in bursts in awake animals and $1.05 \pm 0.12 \mathrm{~Hz}$ with $10.2 \pm 4.3 \%$ of spikes in bursts in anesthetized animals (mean values measured over a $20 \mathrm{~min}$ period before any intervention). These values were not statistically different from each other. Injection of an autoreceptor-selective dose of quinpirole $(100 \mu \mathrm{g} / \mathrm{kg}$, i.p.) (Li et al, 1996; White and Wang, 1983) at the end of the recording session inhibited firing of these neurons by at least 50\% (Supplementary Figure S4).

\section{Effect of $10 \mathrm{mg} / \mathrm{kg}$ i.p. Cocaine on the Firing Rate and Bursting of DA Neurons}

Injection of saline at the beginning of Session 2 (total $n_{\text {units }}=163$; total $n_{\text {rats }}=33$ ) and at the beginning of Session 3 (total $n_{\text {units }}=84$; total $n_{\text {rats }}=16$ ) did not induce any significant changes in the activity of DA neurons in any of the groups (Supplementary Figure S5).

Figure 1 shows that the effect of $10 \mathrm{mg} / \mathrm{kg}$ cocaine on the firing rate of DA neurons was very different in anesthetized and awake animals. This was confirmed by a hierarchical ANOVA test, which yielded a highly significant grouptime interaction for the effect of cocaine in the neurons from awake $v s$ anesthetized animals $\left(\mathrm{F}_{64,4160}=2.26\right.$; $p<0.00001$ ), as well as a significant interaction for cocaine $v s$ saline in the awake $\left(\mathrm{F}_{64,4160}=2.25 ; p<0.00001\right)$ and in the anesthetized animals $\left(\mathrm{F}_{64,4160}=1.55 ; p<0.01\right)$.

Injection of $10 \mathrm{mg} / \mathrm{kg}$ cocaine in anesthetized animals was followed by a decrease in activity of DA neurons (Figure 1). For the whole population $\left(n_{\text {units }}=27, n_{\text {rats }}=7\right.$ ) (Figure 1 , inset), the decrease was significant starting from the 15th minute ( $p<0.05$, Dunnett's post hoc test $v s 5 \mathrm{~min}$ before the drug injection). It was significant starting from the 20th minute $(p<0.05)$ when comparing with the last $5 \mathrm{~min}$ before the injection. Three units in two rats increased their firing rate within $5 \mathrm{~min}$ before the injection. Excluding these three units from the statistical calculations (Figure 1, main panel), the decrease of activity became significant starting from the 25th minute ( $p<0.05 v s 5 \mathrm{~min}$ before the drug injection) or from the 30th minute $(p<0.05 v s$ last $5 \mathrm{~min}$ before the injection).

When considering the whole population of awake rats, injected with $10 \mathrm{mg} / \mathrm{kg}$ cocaine $\left(n_{\text {units }}=52, n_{\text {rats }}=10\right)$, the activity of DA neurons increased after the injection (Figure 1). The increase became significant starting from the 20th minute $(p<0.01$, Dunnett's post hoc test vs $5 \mathrm{~min}$ before the drug injection).

Cocaine, however, induced various patterns of changes in individual DA neurons. This allowed us to separate several subgroups of neurons in each group of rats.

\section{Anesthetized Rats}

In 10 out of $27 \mathrm{DA}$ units, the decrease started at $5 \mathrm{~min}$ after the injection of $10 \mathrm{mg} / \mathrm{kg}$ cocaine, and the activity remained low up to the end of the observation period (Figures 2a and $3 c, d)$. In 6 other units, a sharp short-term increase in activity was observed within $5 \mathrm{~min}$ after the injection. The increase lasted for $10 \mathrm{~min}$ and then the activity declined and remained low until the end of the observation period (Figures $2 \mathrm{~b}$ and $3 \mathrm{a}$ ). This biphasic effect of cocaine on some DA neurons in anesthetized animals was already described previously (Einhorn et al, 1988). The basal activity in these two subgroups of neurons did not differ significantly and 


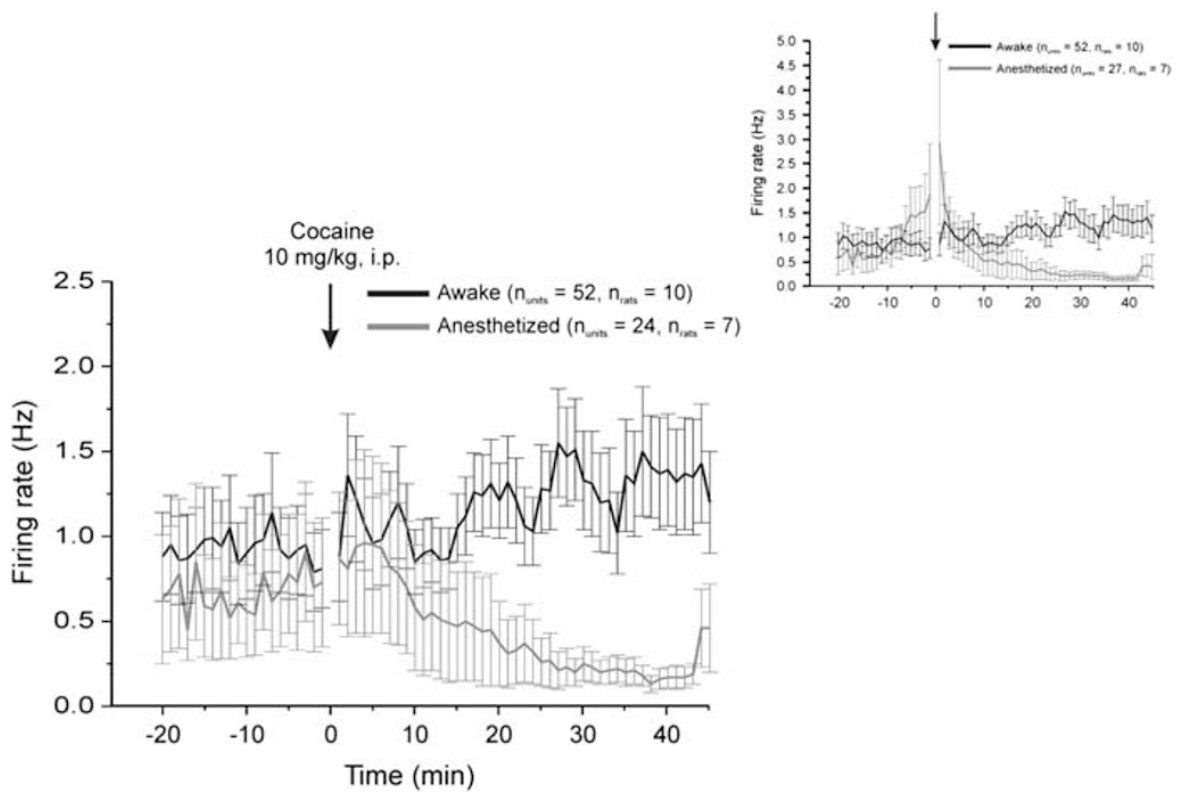

Figure I Effect of cocaine ( $10 \mathrm{mg} / \mathrm{kg}$, intraperitoneally (i.p.)) on the firing rate of dopaminergic (DA) neurons in anesthetized and awake rats. The main panel represents the mean activity of 24 neurons from anesthetized rats. The inset shows the activity from 27 neurons in the anesthetized group. In three of them, an increase in firing rate occurred shortly before the cocaine injection (see text for further details). Error bars represent the standard error of mean (SEM).

a

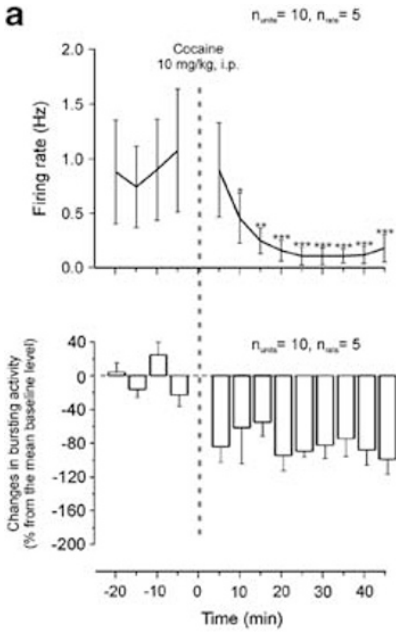

b

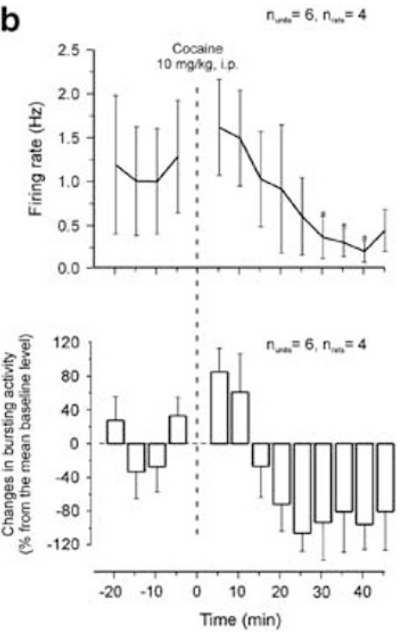

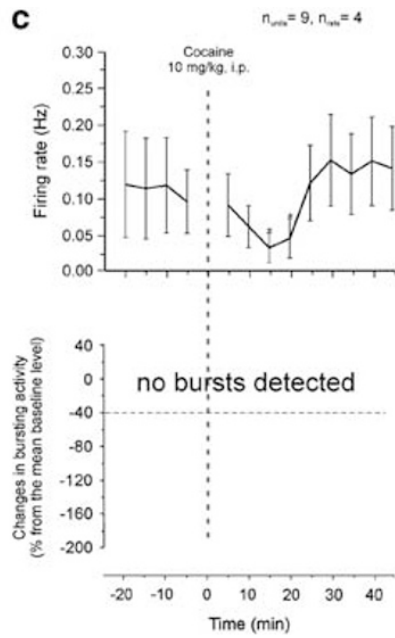

Figure 2 Changes in the firing rate (upper panel) and bursting (lower panel) in dopaminergic (DA) neurons recorded from anesthetized rats after cocaine injection $(10 \mathrm{mg} / \mathrm{kg}$, intraperitoneally (i.p.)). The panels show aggregate data from different subgroups (see text). (a) Units that underwent a steady decrease in firing rate immediately after the injection. (b) Units in which a short excitation was seen before the decrease in firing rate. (c) Units that underwent a shortterm decrease in firing rate. Error bars represent the standard error of mean (SEM). The degree of significance is represented as $* p<0.05$, $* * *<0.01$, **** $p<0.00$ I (Dunnett's test, comparison to the last 5 min before the injection).

was $1.33 \pm 0.14 \mathrm{~Hz}$, with $8.3 \pm 4.8 \%$ of spikes in bursts. During the 10 last minutes of the observation period, the firing rate had decreased to $0.23 \pm 0.12 \mathrm{~Hz}$ with $0.8 \pm 0.6 \%$ of spikes in bursts.

In 9 units the activity decreased within $5 \mathrm{~min}$ after $10 \mathrm{mg} /$ $\mathrm{kg}$ cocaine administration, and recovered 20-25 min after the injection (Figures $2 \mathrm{c}$ and $3 \mathrm{~b}$ ). These neurons had low basal firing rate $(0.11 \pm 0.01 \mathrm{~Hz})$ and did not express any bursting activity.

In two DA neurons, the injection of cocaine was followed by an increase in firing rate from 1.05 and 0.83 to 2.16 and $1.24 \mathrm{~Hz}$, respectively. No bursting activity was detected in these neurons.

\section{Non-Anesthetized Rats}

Patterns of changes induced by cocaine in DA neurons from awake rats were much more variable than in anesthetized animals.

In Subgroup 1 (15 units, from 7 animals), injection of cocaine led to a gradual increase in firing rate. The increase lasted up to the end of the $45 \mathrm{~min}$ observation period and was significant from the 20th minute $(p<0.05-0.01$, Dunnett's test; Figure 4a). In LCR animals, these units had significantly $(p<0.05$, ANOVA) lower basal firing rates $\left(0.23 \pm 0.02 \mathrm{~Hz} ; n_{\text {units }}=7, n_{\text {rats }}=4\right)$ than in HCR animals $\left(1.12 \pm 0.07 \mathrm{~Hz} ; n_{\text {units }}=8, n_{\text {rats }}=3\right)$. Firing rates increased 

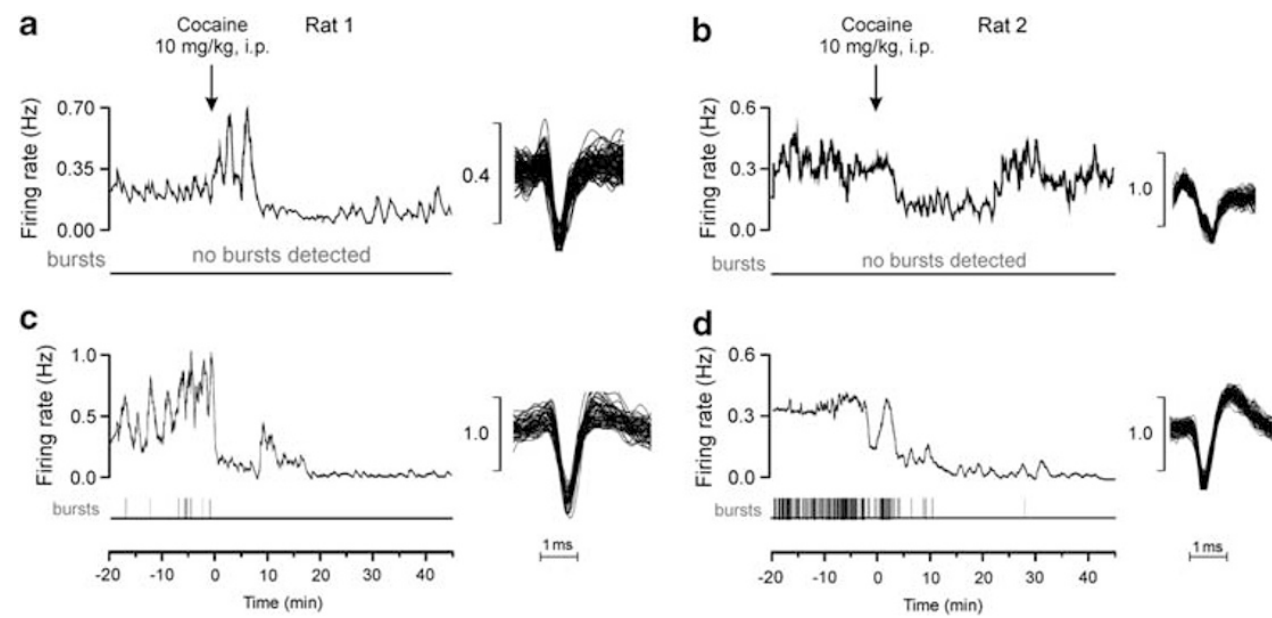

Figure 3 Examples of the effect of a systemic cocaine injection on the firing rate and bursting in two different rats during chloral hydrate anesthesia. Each vertical bar at the bottom of the panels represents an individual burst event (see Materials and methods).

a

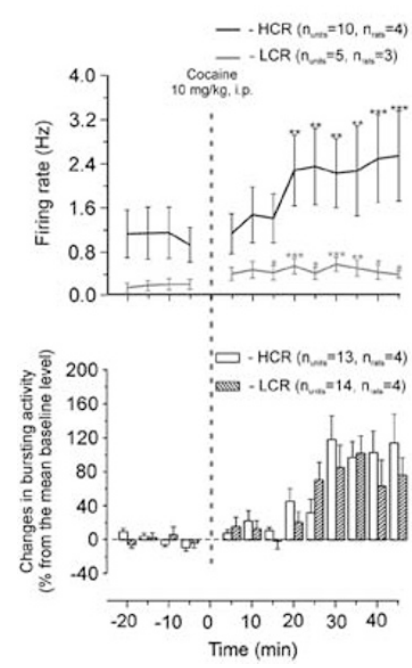

b

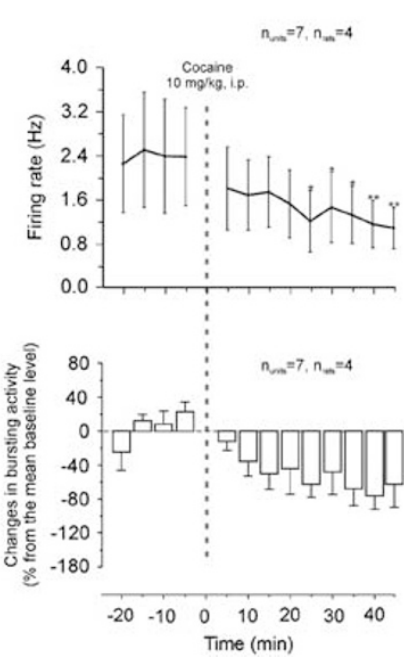

C

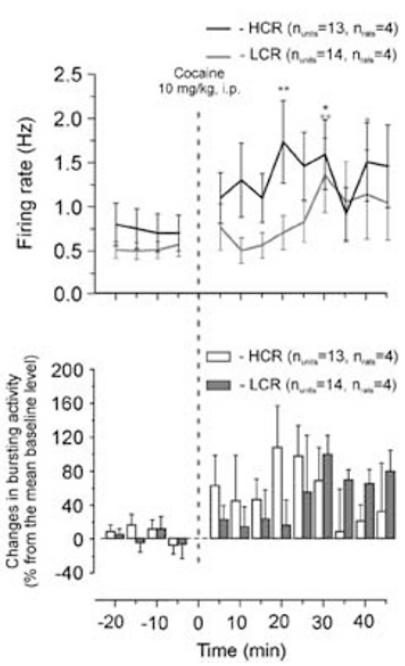

Figure 4 Changes in the firing rate and bursting in dopaminergic (DA) neurons recorded from awake rats after cocaine injection (I0 mg/kg, intraperitoneally (i.p.)). (a) Units that underwent an increase in firing rate without correlation to locomotor activity. (b) Units in which a decrease in firing rate was observed. (c) Units in which the increase in firing rate was correlated to locomotor activation. Error bars represent the standard error of mean (SEM). The degree of significance is represented as $* p<0.05$, ** $p<0.01$, **** $p<0.00$ I (Dunnett's test, comparison to the last 5 min before the injection).

up to $0.45 \pm 0.05 \mathrm{~Hz}$ in LCR rats and up to $2.66 \pm 0.09 \mathrm{~Hz}$ in HCR rats.

In Subgroup 2 (7 units, from 4 animals), after the injection of cocaine, we observed a significant decrease in activity, similar to the main tendency in anesthetized animals ( $p<0.05-0.01$, Dunnett's test from the 20th minute; Figure $4 \mathrm{~b}$ ). Baseline activities of these neurons did not differ significantly in LCR and HCR animals.

Changes in the activity in these two subgroups of neurons did not correlate with the level of the animals' locomotor activity (see examples in Figure 5).

The activity in Subgroup 3 (27 units, from 8 animals) fluctuated. This was the only subgroup of neurons in which the firing rate was positively correlated to the locomotor activity (see Figure 5 for examples). Separate averaging of the activity recorded from HCR and LCR rats showed no significant difference in the basal firing rate of these neurons. However, DA neurons recorded from LCR rats $\left(n_{\text {units }}=14, n_{\text {rats }}=4\right)$ underwent an increase in firing and bursting, which was delayed as compared with those from HCR animals $\left(n_{\text {units }}=13, n_{\text {rats }}=4\right)$, consistent with the slower onset of locomotor activation of the former animals (Figures $4 \mathrm{c}$ and 5).

The mean basal firing rate of the neurons in awake rats was different in the three subgroups $(\mathrm{F}=7,53, p<0.01$, hierarchical ANOVA). It was significantly higher in Subgroup $2(2.32 \pm 0.22 \mathrm{~Hz}$ with $26.5 \pm 9.3 \%$ of spikes in bursts) than in Subgroup 1 (for the whole population, $0.71 \pm 0.07 \mathrm{~Hz}$ with $5.6 \pm 3.5 \%$ of spikes in bursts; $p<0.05$, Dunnett's post hoc test), and in Subgroup 3 (for the whole population, $0.64 \pm 0.07 \mathrm{~Hz}$ with $6.2 \pm 3.2 \%$ of spikes in bursts; $p<0.05$, Dunnett's post hoc test). 

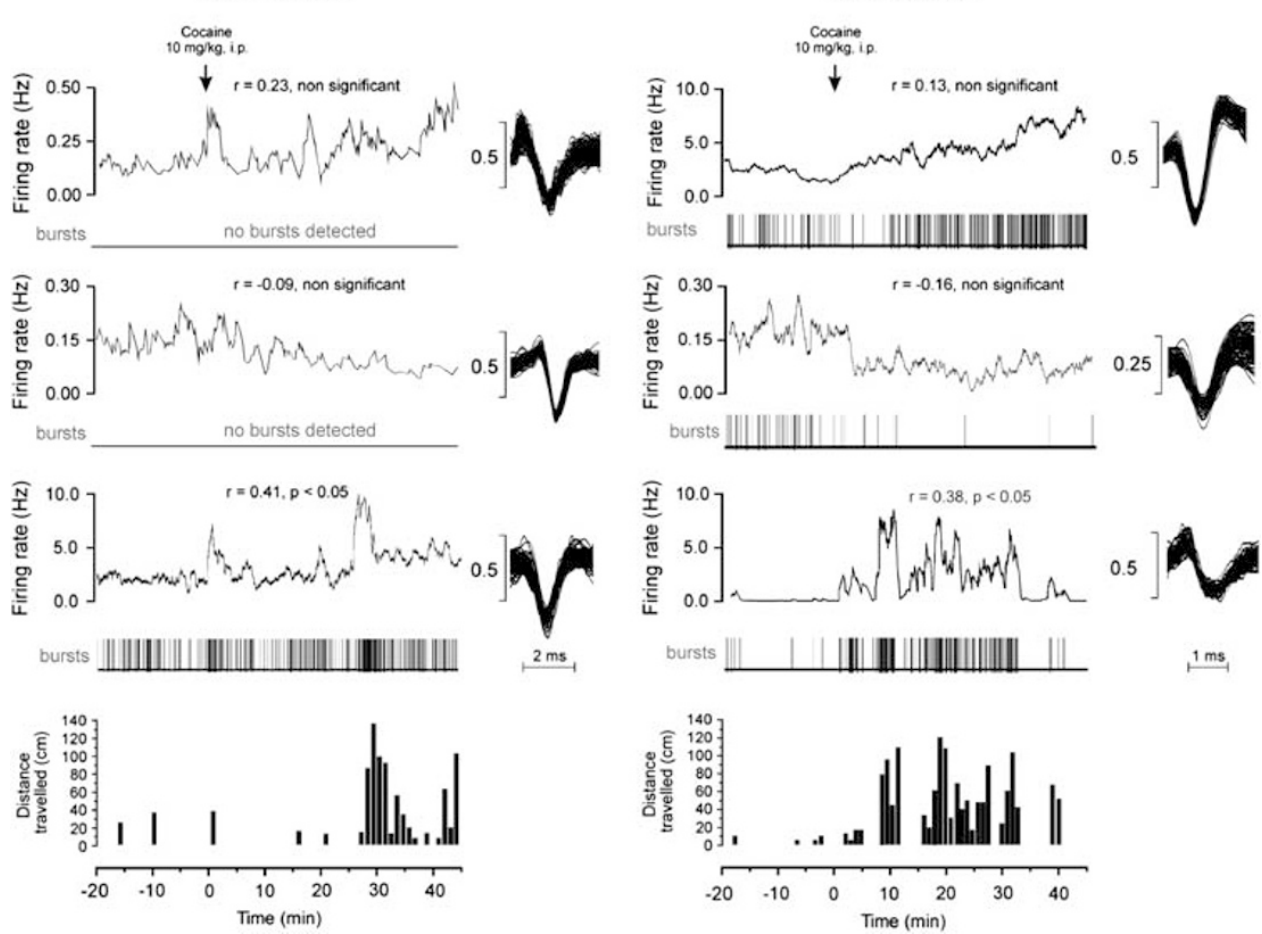

Figure 5 Examples of the effect of cocaine $(10 \mathrm{mg} / \mathrm{kg}$, intraperitoneally (i.p.)) on the firing rate, bursting, and locomotor activity in a low cocaineresponsive (LCR) and a high cocaine-responsive (HCR) rat. The degree of correlation between firing rate and locomotor activity (Pearson's coefficient) is indicated for each cell.

The last small subgroup consisted of 3 units (from 2 animals) in which firing rate and bursting decreased within $10 \mathrm{~min}$ after the injection of $10 \mathrm{mg} / \mathrm{kg}$ cocaine, and returned to the initial level when the locomotor activity of the animals increased at 20-25 min after the drug injection.

\section{Effect of $1 \mathrm{mg} / \mathrm{kg}$ i.p. Cocaine on the Behavior and DA Neurons}

In anesthetized rats $\left(n_{\text {units }}=13, n_{\text {rats }}=5\right)$, i.p. injection of $1 \mathrm{mg} / \mathrm{kg}$ cocaine was followed by a slight decrease in firing rate and bursting of DA in two neurons, and a slight increase in firing rate and bursting of DA in one neurons (Supplementary Figure S6A). Other recorded neurons did not show significant changes in activity after the cocaine injection within the period of observation.

In awake animals ( $\left.n_{\text {units }}=11, n_{\text {rats }}=5\right)$, this dose of cocaine led to an increase of activity in one neuron and decrease in another one (Supplementary Figure S6B). Other DA neurons did not undergo significant changes in either firing rate or bursting. These animals also did not show significant changes in the locomotor behavior $45 \mathrm{~min}$ after the injection of cocaine. Overall, this dose of i.p. cocaine did not induce any significant electrophysiological effect.

\section{Effect of General Anesthesia on DA Neurons}

Injection of chloral hydrate $(400 \mathrm{mg} / \mathrm{kg}$, i.p.) in four awake animals during the recording was followed by a fast inhibition of 7 out of 10 DA neurons ( 3 out of 5,1 out of 1,1 out of 2 , and 2 out of 2 , respectively). The firing rate of three out of these seven neurons was completely inhibited and recovered only by the end of the anesthesia period (see examples in Figure 6).

\section{Results of Pharmacokinetic Study}

There were no significant differences in cocaine concentrations between the awake and anesthetized rats in either plasma or brain tissue. Between the 10th and the 30th minute, the concentration of the drug decreased by $50-60 \%$ (Figure 7).

BZE concentrations in the plasma were significantly lower in anesthetized animals than in awake rats. Cocaine/BZE ratios in the plasma of anesthetized animals were $>>1$ in contrast to $<<1$ in the awake group. This suggests that breakdown of cocaine was inhibited under chloral hydrate anesthesia, which is in accordance with the finding by other groups that chloral hydrate inhibits cocaine esterase (Benuck et al, 1989; Pan et al, 1995), the enzyme forming BZE from cocaine (Mets et al, 1999).

In the brain, BZE concentrations were also higher in awake animals at $30 \mathrm{~min}(p<0.01$, Student's $t$-test $)$ (Figure 7). However, cocaine/BZE ratios in the brain were $>>10$ for both groups, suggesting that different BZE concentrations are unlikely to explain the different effects of the cocaine injection in the two groups.

\section{DISCUSSION}

\section{General Findings}

The results of this study demonstrate that an acute injection of cocaine differentially affects midbrain DA neurons in awake and anesthetized rats. 

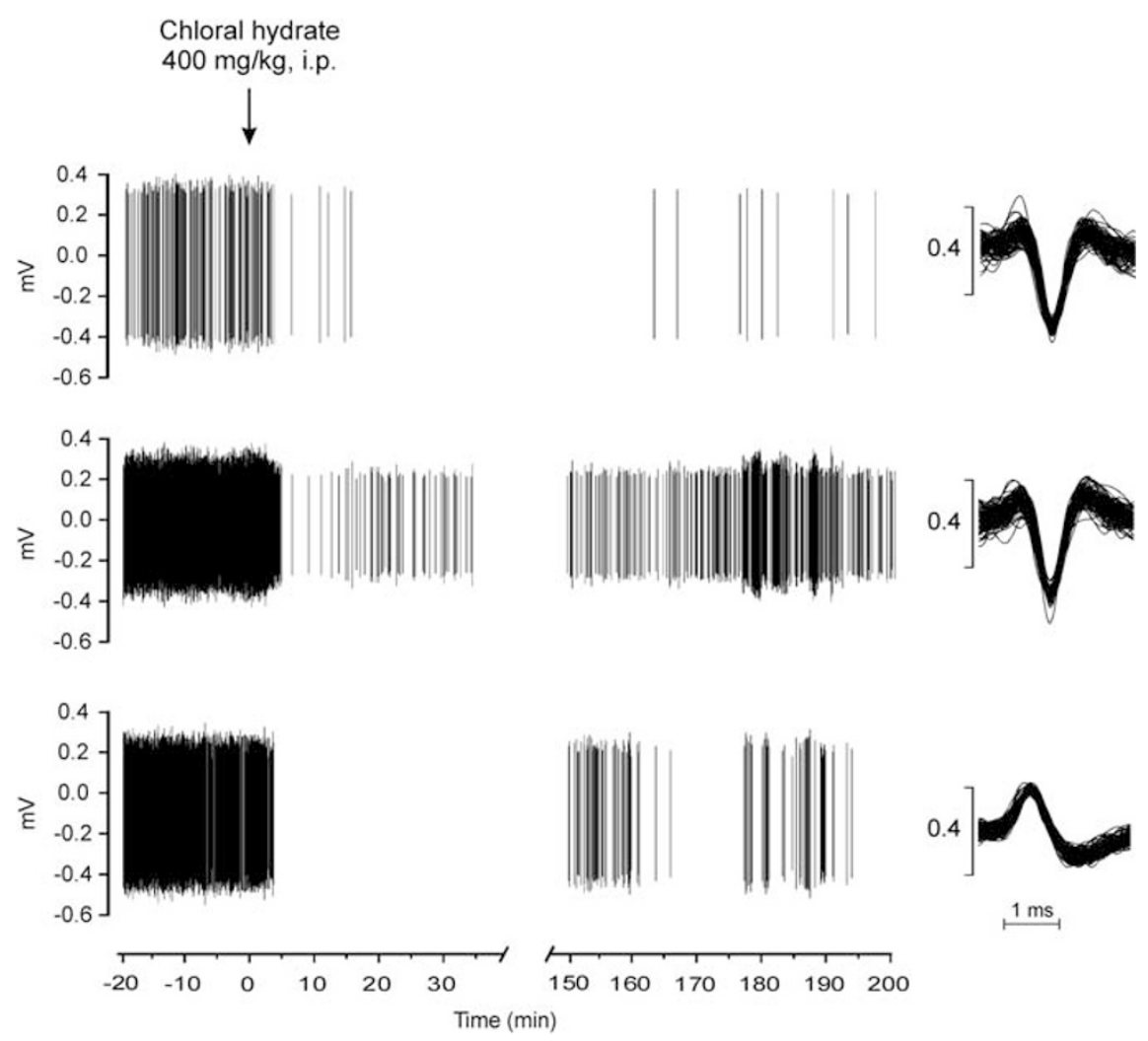

Figure 6 Examples of the effect of chloral hydrate anesthesia $(400 \mathrm{mg} / \mathrm{kg}$, intraperitoneally (i.p.)) on the activity of dopaminergic (DA) neurons in one rat.
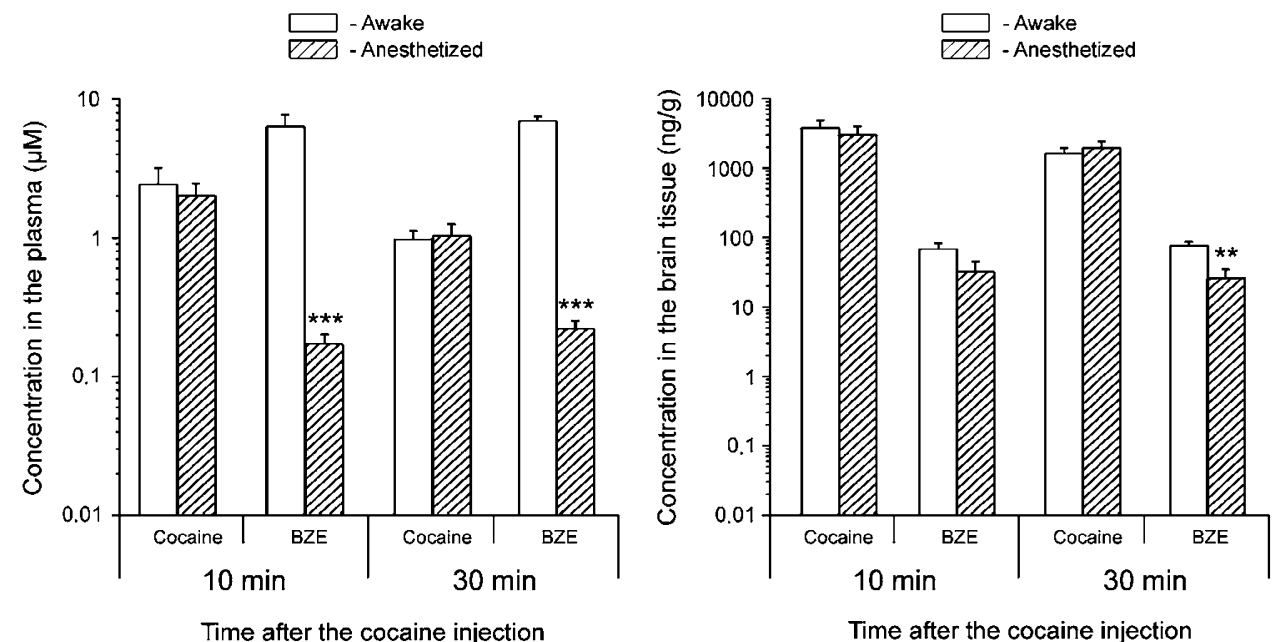

Figure 7 Concentration of cocaine and benzoylecgonine in the plasma and brain tissue of awake and chloral hydrate-anesthetized rats, 10 and 30 min after an intraperitoneal (i.p.) injection of $10 \mathrm{mg} / \mathrm{kg}$ cocaine. Results are expressed on a logarithmic scale as means \pm standard error of mean (SEM). *** $p<0.01$, ***** $p<0.001$.

In anesthetized rats, the i.p. injection of $10 \mathrm{mg} / \mathrm{kg}$ cocaine led to a decrease in firing rate and bursting in most of the recorded neurons. This is an anticipated effect, consistent with the knowledge about autoregulatory mechanisms within the mesolimbic pathways (Kalivas, 1993; Wang, 1981; White and Wang, 1984a, b, 1986) and congruent with the action of cocaine on the dopamine transporter (Kuhar et al, 1991). It is consistent with previous electrophysiological experiments conducted in vivo under general anesthesia
(Einhorn et al, 1988; Hinerth et al, 2000; Mercuri et al, 1992).

By contrast, in non-anesthetized rats, injection of the same dose of cocaine increased the firing rate and bursting of a majority of DA neurons.

As discussed below, a number of mechanisms may account for the excitatory effects of cocaine in awake animals. We will discuss separately the two patterns of excitatory effects. 


\section{Excitatory Effect of Cocaine on DA Neurons in Non-Anesthetized Rats}

The most intriguing observation of our study was that $29 \%$ of DA neurons in the VTA (Subgroup 1) of awake rats underwent a steady increase in firing rate without any significant correlation to locomotor activity. To our knowledge, this effect has never been described before, and it was not observed in anesthetized animals in our hands.

One attractive explanation for this result is the induction of a long-term potentiation of glutamatergic synapses on DA neurons. Such a phenomenon has been observed after a single exposure to cocaine in brain slices (Ungless et al, 2001). This potentiation has at least two phases, involving NMDA and AMPA receptors, respectively (Argilli et al, 2008). Enhancement of NMDA-mediated transmission can be already measured within a few minutes (Argilli et al, 2008; Schilstrom et al, 2006), thus having a time course that is compatible with the one of our experiments (Figure 4a), suggesting that these events might have a similar origin. Schilstrom et al (2006) found that cocaine-induced NMDA potentiation is due to the activation of protein kinase A via D5 receptors, located on the membrane of VTA DA neurons. It will therefore be interesting in future experiments to test whether co-treatment with a D1/D5 antagonist prevents this pattern of excitation of VTA DA neurons after cocaine injection in awake animals.

It should also be remembered that several VTA-projecting areas release neurotransmitters that are able to excite DA neurons (Geisler et al, 2007; Mathon et al, 2003; White, 1996). Geisler et al (2008) demonstrated that at least some of these afferents are activated in awake animals by repeated cocaine administration, which can in turn lead to the activation of VTA DA cells. General anesthesia can abolish this effect of cocaine, as it markedly decreases the activity of many central neurons. This can explain the difference between awake and anesthetized rats in our experiments.

There are other possible explanations for the stimulating effect of cocaine on the VTA DA neurons. Because it is a local anesthetic (O'Leary and Chahine, 2002), the drug can use-dependently inhibit faster-firing GABAergic neurons in the VTA, thus decreasing the inhibitory input to the DA neurons (Steffensen et al, 2008). However, the local anesthetic effect of cocaine may require higher concentrations of the drug in the brain tissue than those achieved in our experiments (Strichartz, 1976). Another possibility is that, by blocking the serotonin transporter (Reith et al, 1986; Ritz et al, 1990), cocaine may increase the concentration of serotonin in the VTA (Reith et al, 1997a), leading to the activation of inhibitory presynaptic $5 \mathrm{HT}_{1 \mathrm{D}}$ receptors on GABA terminals (Cameron and Williams, 1994; Johnson et al, 1992), and therefore disinhibition of DA neurons.

A final explanation is provided by the block of the noradrenaline transporter by the drug. The concentration of noradrenaline is known to increase after the injection of cocaine (Reith et al, 1997a). This could increase the spontaneous firing rate in VTA DA neurons, by activating $\alpha_{1}$ receptors (Grenhoff et al, 1995).

In $52 \%$ (27 out of 52) of DA units (Subgroup 3), both firing rate and bursting fluctuated, with a clear correlation to the locomotor activity of the animals. We do not know whether fluctuations in the activity of these neurons were secondary to the cocaine-induced locomotor effects, or whether changes in their firing underlied locomotor activation. The fact that VTA neurons play an important role in motivation makes the latter interpretation very attractive, but this issue needs further investigation.

\section{Differences Between Rats Classified as HCR or LCR}

Behavioral effects of cocaine that were observed in this study are in a good agreement with previous observations in Sprague-Dawley rats (Gulley et al, 2003; Mandt and Zahniser, 2010; Sabeti et al, 2002).

We would also like to emphasize the difference observed in the basal firing rate of the Subgroup 1 neurons recorded from LCR and HCR rats. In LCR animals, these neurons had lower basal firing rates than in HCR rats (Figure 4a). Similar differences in the basal firing rate were reported for VTA DA neurons between rats expressing a low and high reaction to novelty (McCutcheon et al, 2009). Interestingly, animals exhibiting a higher response to novelty also have an enhanced susceptibility to addiction (Belin et al, 2009; Cain et al, 2004; Grimm and See, 1997; Marinelli and White, 2000; Piazza et al, 1989, 1990, 2000; Pierre and Vezina, 1997; Stoffel and Cunningham, 2008). Moreover, the reactivity of their VTA DA neurons is suggested to be critical for the development of addictive behavior (Marinelli et al, 2003, 2006; Marinelli and White, 2000; McCutcheon et al, 2009; Vezina, 2004; White and Kalivas, 1998a).

Although the relationship between the levels of locomotor response to novelty and of cocaine-induced locomotion remains controversial (Allen et al, 2007; Chefer et al, 2003; Gulley et al, 2003; Hooks et al, 1991; Mercuri et al, 1989; Sabeti et al, 2002), our findings suggest a possible common substratum of these two types of behavior.

Physiological mechanisms underlying lower and higher behavioral reactivity to cocaine are not completely clear. The diversity of locomotor reactivity might be due to a recently demonstrated difference in the levels of DAT activity in the NAc and striatum (Sabeti et al, 2002), leading to different extracellular DA levels (Nelson et al, 2009).

\section{Possible Role of the Recorded DA Neurons in Reinforcing and Behavioral Effects of Cocaine}

DA neurons from the caudal and dorsal VTA send projections to the ventral regions of the striatum, particularly to the NAc (Beckstead et al, 1979; Fallon and Moore, 1978; Ikemoto, 2007; Koob, 1992; Pierce and Kumaresan, 2006; Swanson, 1982). DA cells from the lateral portion of VTA mostly project to the ventral pallidum (Klitenick et al, 1992). Both NAc and ventral pallidum play a key role in drug addiction (Hubner and Koob, 1990; Koob, 1992; Robinson and Berridge, 2003). We suggest that those DA neurons in the dorsocaudal VTA, which expressed steady activation after $10 \mathrm{mg} / \mathrm{kg}$ cocaine injection in our experiments (Figure 4a), represent a part of the drug reinforcement circuit. Further studies are needed to evaluate possible relationship between the difference in the basal firing rate of these neurons observed in LCR and HCR rats and vulnerability of animals to the reinforcing effect of the drug.

At the same time, mesopallidal DA projections play a role in the maintenance of locomotor activity, and 
microinjections of DA into the ventral pallidum were shown to stimulate locomotion (Klitenick et al, 1992). It is possible that neurons from Subgroup 3 (Figure 4c) in our study belonged to this population.

\section{Effect of General Anesthesia}

Differences between drug effects in awake and anesthetized animals have been reported in other brain areas. For example, cocaine increases the activity of striatal and accumbal neurons in freely moving animals (Kiyatkin, 2002; Kiyatkin and Rebec, 2000; Pederson et al, 1997; White et al, 1998b), but decreases their firing in anesthetized ones (Kreuter et al, 2004).

Chloral hydrate anesthesia has often been used in electrophysiological experiments on DA neurons (Einhorn et al, 1988; Freeman et al, 1989; Grace and Bunney, 1984; Shepard and German, 1988). The reason is that the pattern of activity of DA neurons recorded from chloral hydrateanesthetized animals is relatively similar to the pattern of activity of DA neurons recorded from animals in the awake state (Freeman and Bunney, 1987; Hyland et al, 2002). This led to the assumption that chloral hydrate has a mild effect on the afferent synaptic inputs to the midbrain DA neurons. However, the tone of afferent inputs in anesthetized animals is probably different from the one in behaving animals, as anesthesia changes the activity and sensitivity of different components of central circuitry, including those sending afferent projections to the midbrain DA system (Hamilton et al, 1992; Heym et al, 1984; Kreuter et al, 2004; Trulson and Trulson, 1983a, b; Warenycia and McKenzie, 1984).

Moreover, chloral hydrate does affect midbrain DA neurons themselves, altering their responsiveness to various centrally acting drugs (Bunney et al, 1973a; Gessa et al, 1985; Kelland et al, 1990, 1989; Melis et al, 1998; Mereu et al, 1987), particularly enhancing the ability of DA agonists to inhibit activity of DA neurons (Kelland et al, 1989).

A clear effect of chloral hydrate on DA neurons was observed in our study. Indeed, a majority of the DA neurons recorded in awake rats were partly or fully suppressed by chloral hydrate injection (Figure 6). At the same time, we did not find significant differences in the baseline firing rate of DA neurons between awake and anesthetized animals (Figure 1). Collectively, these observations suggest that populations of DA neurons recorded in the awake and anesthetized animals were different - a large fraction of the DA neurons, contributing to the firing rate under general anesthesia, were silent in the awake state, and vice versa. This would explain the difference in the cocaine effects, especially in view of the recent observation that the properties of glutamatergic synapses onto the various subpopulations of VTA DA neurons are heterogeneous (Lammel et al, 2011).

Anesthesia also excludes stress, which is known to affect the DA system. In the awake animals, a mild stress could potentiate DA neuron firing, as has been shown for mesoprefrontal neurons (Thierry et al, 1976). However, we tried to minimize stress by careful habituation of the rats before the experimental sessions. We therefore do not favor this explanation as a reason for the observed differences.

\section{Lack of Effect of Anesthesia on Brain Cocaine Concentrations}

The previously demonstrated ability of general anesthesia to alter cocaine metabolism (Benuck et al, 1989; Pan et al, 1995) suggested that differences in the cocaine effects between awake and anesthetized rats might have a pharmacokinetic origin. We found the expected difference in plasma BZE concentrations, which is explained by the inhibition of cocaine esterase by chloral hydrate (Benuck et al, 1989; Pan et al, 1995). However, cocaine concentrations in the brain were not significantly different in the awake and anesthetized animal, and were much higher than the concentration of BZE. These results allow us to suggest that the differences observed in our electrophysiological experiments have a pharmacodynamic rather than a pharmacokinetic origin.

\section{CONCLUSIONS}

This study demonstrates strikingly different effects of i.p. injected cocaine on the activity of DA neurons in awake and anesthetized animals. Such a difference is also likely to exist for other drugs of abuse. Telemetric recordings in awake animals may allow investigators to uncover drug effects, which are masked by anesthetics because of a general decrease in neuronal excitability and connectivity. It will be interesting in the future to study possible changes in DA neuron excitability during cocaine reinforcement in selfadministration protocols.

\section{ACKNOWLEDGEMENTS}

This work was supported by Grant No. 9.4560 .03 from the F.R.S-FNRS (VS) and by a grant from the Belgian Science Policy (IAP 6/31) (VS). We thank Dr. Nancy Zahniser (University of Colorado, Denver, CO) and Dr. Philippe Alix (University of Liège, Belgium) for their valuable comments on the manuscript. We also appreciate technical support and advices provided by Alpha Omega GmbH.

\section{DISCLOSURE}

The authors declare no conflict of interest.

\section{REFERENCES}

Allen RM, Everett CV, Nelson AM, Gulley JM, Zahniser NR (2007). Low and high locomotor responsiveness to cocaine predicts intravenous cocaine conditioned place preference in male Sprague-Dawley rats. Pharmacol Biochem Behav 86: 37-44.

Argilli E, Sibley DR, Malenka RC, England PM, Bonci A (2008). Mechanism and time course of cocaine-induced long-term potentiation in the ventral tegmental area. J Neurosci 28: 9092-9100.

Beckstead RM, Domesick VB, Nauta WJ (1979). Efferent connections of the substantia nigra and ventral tegmental area in the rat. Brain Res 175: 191-217.

Belin D, Balado E, Piazza PV, Deroche-Gamonet V (2009). Pattern of intake and drug craving predict the development of cocaine addiction-like behavior in rats. Biol Psychiatry 65: 863-868. 
Benuck M, Reith ME, Sershen H, Wiener HL, Lajtha A (1989). Oxidative metabolism of cocaine: comparison of brain and liver. Proc Soc Exp Biol Med 190: 7-13.

Berretta N, Bernardi G, Mercuri NB (2010). Firing properties and functional connectivity of substantia nigra pars compacta neurones recorded with a multi-electrode array in vitro. J Physiol 588(Part 10): 1719-1735.

Bowman BP, Vaughan SR, Walker QD, Davis SL, Little PJ, Scheffler NM et al (1999). Effects of sex and gonadectomy on cocaine metabolism in the rat. J Pharmacol Exp Ther 290: 1316-1323.

Bradberry CW, Roth RH (1989). Cocaine increases extracellular dopamine in rat nucleus accumbens and ventral tegmental area as shown by in vivo microdialysis. Neurosci Lett 103: 97-102.

Broderick PA, Kornak Jr EP, Eng F, Wechsler R (1993). Real time detection of acute (IP) cocaine-enhanced dopamine and serotonin release in ventrolateral nucleus accumbens of the behaving Norway rat. Pharmacol Biochem Behav 46: 715-722.

Brodie MS, Dunwiddie TV (1990). Cocaine effects in the ventral tegmental area: evidence for an indirect dopaminergic mechanism of action. Naunyn-Schmiedeberg's ArchPharmacol 342: 660-665.

Bunney BS, Aghajanian GK, Roth RH (1973a). Comparison of effects of L-dopa, amphetamine and apomorphine on firing rate of rat dopaminergic neurones. Nature 245: 123-125.

Bunney BS, Walters JR, Roth RH, Aghajanian GK (1973b). Dopaminergic neurons: effect of antipsychotic drugs and amphetamine on single cell activity. J Pharmacol Exp Ther 185: 560-571.

Cain ME, Smith CM, Bardo MT (2004). The effect of novelty on amphetamine self-administration in rats classified as high and low responders. Psychopharmacology (Berl) 176: 129-138.

Cameron DL, Williams JT (1994). Cocaine inhibits GABA release in the VTA through endogenous 5-HT. J Neurosci 14(Part 1): 6763-6767.

Carelli RM (2002). Nucleus accumbens cell firing during goaldirected behaviors for cocaine vs natural reinforcement. Physiol Behav 76: 379-387.

Carelli RM, Deadwyler SA (1994). A comparison of nucleus accumbens neuronal firing patterns during cocaine selfadministration and water reinforcement in rats. $J$ Neurosci 14: 7735-7746.

Chefer VI, Zakharova I, Shippenberg TS (2003). Enhanced responsiveness to novelty and cocaine is associated with decreased basal dopamine uptake and release in the nucleus accumbens: quantitative microdialysis in rats under transient conditions. J Neurosci 23: 3076-3084.

Chiodo LA, Bannon MJ, Grace AA, Roth RH, Bunney BS (1984). Evidence for the absence of impulse-regulating somatodendritic and synthesis-modulating nerve terminal autoreceptors on subpopulations of mesocortical dopamine neurons. Neuroscience 12: 1-16.

Clark D, Chiodo LA (1988). Electrophysiological and pharmacological characterization of identified nigrostriatal and mesoaccumbens dopamine neurons in the rat. Synapse 2: 474-485.

Clark D, Hjorth S, Carlsson A (1985a). Dopamine-receptor agonists: mechanisms underlying autoreceptor selectivity. I. Review of the evidence. J Neural Transm 62: 1-52.

Clark D, Hjorth S, Carlsson A (1985b). Dopamine receptor agonists: mechanisms underlying autoreceptor selectivity. II. Theoretical considerations. J Neural Transm 62: 171-207.

Cohen I, Miles R (2000). Contributions of intrinsic and synaptic activities to the generation of neuronal discharges in in vitro hippocampus. J Physiol 524(Part 2): 485-502.

Einhorn LC, Johansen PA, White FJ (1988). Electrophysiological effects of cocaine in the mesoaccumbens dopamine system: studies in the ventral tegmental area. J Neurosci 8: 100-112.

Fallon JH, Moore RY (1978). Catecholamine innervation of the basal forebrain. IV. Topography of the dopamine projection to the basal forebrain and neostriatum. J Comp Neurol 180: $545-580$.

Ford CP, Williams JT (2008). Mesoprefrontal dopamine neurons distinguish themselves. Neuron 57: 631-632.

Freeman AS, Bunney BS (1987). Activity of A9 and A10 dopaminergic neurons in unrestrained rats: further characterization and effects of apomorphine and cholecystokinin. Brain Res 405: 46-55.

Freeman AS, Kelland MD, Rouillard C, Chiodo LA (1989). Electrophysiological characteristics and pharmacological responsiveness of midbrain dopaminergic neurons of the aged rat. J Pharmacol Exp Ther 249: 790-797.

Freye E, Levy JV (2009). Pharmacology and Abuse of Cocaine, Amphetamines, Ecstasy and Related Designer Drugs: A Comprehensive Review on Their Mode of Action. Treatment of Abuse and Intoxication Springer: Düsseldorf, Germany.

Geisler S, Derst C, Veh RW, Zahm DS (2007). Glutamatergic afferents of the ventral tegmental area in the rat. J Neurosci 27: $5730-5743$.

Geisler S, Marinelli M, Degarmo B, Becker ML, Freiman AJ, Beales $M$ et al (2008). Prominent activation of brainstem and pallidal afferents of the ventral tegmental area by cocaine. Neuropsychopharmacology 33: 2688-2700.

Gessa GL, Muntoni F, Collu M, Vargiu L, Mereu G (1985). Low doses of ethanol activate dopaminergic neurons in the ventral tegmental area. Brain Res 348: 201-203.

Gold C, Henze DA, Koch C, Buzsaki G (2006). On the origin of the extracellular action potential waveform: a modeling study. J Neurophysiol 95: 3113-3128.

Grace AA, Bunney BS (1984). The control of firing pattern in nigral dopamine neurons: burst firing. J Neurosci 4: 2877-2890.

Grenhoff J, North RA, Johnson SW (1995). Alpha 1-adrenergic effects on dopamine neurons recorded intracellularly in the rat midbrain slice. Eur J Neurosci 7: 1707-1713.

Grimm JW, See RE (1997). Cocaine self-administration in ovariectomized rats is predicted by response to novelty, attenuated by 17-beta estradiol, and associated with abnormal vaginal cytology. Physiol Behav 61: 755-761.

Gulley JM, Hoover BR, Larson GA, Zahniser NR (2003). Individual differences in cocaine-induced locomotor activity in rats: behavioral characteristics, cocaine pharmacokinetics, and the dopamine transporter. Neuropsychopharmacology 28: 2089-2101.

Hamilton ME, Mele A, Pert A (1992). Striatal extracellular dopamine in conscious vs. anesthetized rats: effects of chloral hydrate anesthetic on responses to drugs of different classes. Brain Res 597: 1-7.

Heym J, Steinfels GF, Jacobs BL (1984). Chloral hydrate anesthesia alters the responsiveness of central serotonergic neurons in the cat. Brain Res 291: 63-72.

Hinerth MA, Collins HA, Baniecki M, Hanson RN, Waszczak BL (2000). Novel in vivo electrophysiological assay for the effects of cocaine and putative 'cocaine antagonists' on dopamine transporter activity of substantia nigra and ventral tegmental area dopamine neurons. Synapse 38: 305-312.

Hooks MS, Jones GH, Smith AD, Neill DB, Justice Jr JB (1991). Response to novelty predicts the locomotor and nucleus accumbens dopamine response to cocaine. Synapse 9: 121-128.

Horger BA, Iyasere CA, Berhow MT, Messer CJ, Nestler EJ, Taylor JR (1999). Enhancement of locomotor activity and conditioned reward to cocaine by brain-derived neurotrophic factor. J Neurosci 19: 4110-4122.

Hubner CB, Koob GF (1990). The ventral pallidum plays a role in mediating cocaine and heroin self-administration in the rat. Brain Res 508: 20-29.

Hyland BI, Reynolds JN, Hay J, Perk CG, Miller R (2002). Firing modes of midbrain dopamine cells in the freely moving rat. Neuroscience 114: 475-492. 
Ikemoto S (2007). Dopamine reward circuitry: two projection systems from the ventral midbrain to the nucleus accumbensolfactory tubercle complex. Brain Res Rev 56: 27-78.

Johnson SW, Mercuri NB, North RA (1992). 5-Hydroxytryptamine1B receptors block the GABAB synaptic potential in rat dopamine neurons. J Neurosci 12: 2000-2006.

Kalivas PW (1993). Neurotransmitter regulation of dopamine neurons in the ventral tegmental area. Brain Res Rev 18: 75-113.

Kelland MD, Chiodo LA, Freeman AS (1990). Anesthetic influences on the basal activity and pharmacological responsiveness of nigrostriatal dopamine neurons. Synapse 6: 207-209.

Kelland MD, Freeman AS, Chiodo LA (1989). Chloral hydrate anesthesia alters the responsiveness of identified midbrain dopamine neurons to dopamine agonist administration. Synapse 3: 30-37.

Kiyatkin EA (2002). Dopamine in the nucleus accumbens: cellular actions, drug- and behavior-associated fluctuations, and a possible role in an organism's adaptive activity. Behav Brain Res 137: 27-46.

Kiyatkin EA, Rebec GV (2000). Dopamine-independent action of cocaine on striatal and accumbal neurons. Eur J Neurosci 12: 1789-1800.

Klitenick MA, Deutch AY, Churchill L, Kalivas PW (1992). Topography and functional role of dopaminergic projections from the ventral mesencephalic tegmentum to the ventral pallidum. Neuroscience 50: 371-386.

Koob GF (1992). Drugs of abuse: anatomy, pharmacology and function of reward pathways. Trends Pharmacol Sci 13: 177-184.

Krebs RM, Heipertz D, Schuetze H, Duzel E (2011). Novelty increases the mesolimbic functional connectivity of the substantia nigra/ventral tegmental area (SN/VTA) during reward anticipation: evidence from high-resolution fMRI. NeuroImage 58: 647-655.

Kreuter JD, Mattson BJ, Wang B, You ZB, Hope BT (2004). Cocaine-induced Fos expression in rat striatum is blocked by chloral hydrate or urethane. Neuroscience 127: 233-242.

Kuhar MJ, Ritz MC, Boja JW (1991). The dopamine hypothesis of the reinforcing properties of cocaine. Trends Neurosci 14: 299-302.

Lacey MG, Mercuri NB, North RA (1990). Actions of cocaine on rat dopaminergic neurones in vitro. Br J Pharmacol 99: 731-735.

Lammel S, Hetzel A, Hackel O, Jones I, Liss B, Roeper J (2008). Unique properties of mesoprefrontal neurons within a dual mesocorticolimbic dopamine system. Neuron 57: 760-773.

Lammel S, Ion DI, Roeper J, Malenka RC (2011). Projectionspecific modulation of dopamine neuron synapses by aversive and rewarding stimuli. Neuron 70: 855-862.

Lange RA, Hillis LD (2001). Cardiovascular complications of cocaine use. $N$ Engl J Med 345: 351-358.

Li MY, Yan QS, Coffey LL, Reith ME (1996). Extracellular dopamine, norepinephrine, and serotonin in the nucleus accumbens of freely moving rats during intracerebral dialysis with cocaine and other monoamine uptake blockers. J Neurochem 66: 559-568.

Mandt BH, Zahniser NR (2010). Low and high cocaine locomotor responding male Sprague-Dawley rats differ in rapid cocaineinduced regulation of striatal dopamine transporter function. Neuropharmacology 58: 605-612.

Marinelli M, Cooper DC, Baker LK, White FJ (2003). Impulse activity of midbrain dopamine neurons modulates drug-seeking behavior. Psychopharmacology (Berl) 168: 84-98.

Marinelli M, Rudick CN, Hu XT, White FJ (2006). Excitability of dopamine neurons: modulation and physiological consequences. CNS Neurol Disord Drug Targets 5: 79-97.

Marinelli M, White FJ (2000). Enhanced vulnerability to cocaine self-administration is associated with elevated impulse activity of midbrain dopamine neurons. J Neurosci 20: 8876-8885.

Mathon DS, Kamal A, Smidt MP, Ramakers GM (2003). Modulation of cellular activity and synaptic transmission in the ventral tegmental area. Eur J Pharmacol 480: 97-115.
McCutcheon JE, White FJ, Marinelli M (2009). Individual differences in dopamine cell neuroadaptations following cocaine self-administration. Biol Psychiatry 66: 801-803.

Melis M, Mereu G, Lilliu V, Quartu M, Diana M, Gessa GL (1998). Haloperidol does not produce dopamine cell depolarizationblock in paralyzed, unanesthetized rats. Brain Res 783: 127-132.

Mercuri NB, Calabresi P, Bernardi G (1989). The mechanism of amphetamine-induced inhibition of rat substantia nigra compacta neurones investigated with intracellular recording in vitro. Br J Pharmacol 98: 127-134.

Mercuri NB, Calabresi P, Bernardi G (1991). Dopamine uptake inhibition potentiates the effects of L-DOPA on rat substantia nigra zona compacta neurons. Neurosci Lett 126: 79-82.

Mercuri NB, Calabresi P, Bernardi G (1992). The electrophysiological actions of dopamine and dopaminergic drugs on neurons of the substantia nigra pars compacta and ventral tegmental area. Life Sci 51: 711-718.

Mereu G, Fanni B, Gessa GL (1984). General anesthetics prevent dopaminergic nerve stimulation by neuroleptics. In: Usdin $\mathrm{E}$, Carlsson A, Dahlstrdm A, Engel J (eds). Neurology and Neurobiology. Alan R. Liss: New York, Vol. 8B, pp 353-358.

Mereu G, Yoon KW, Boi V, Gessa GL, Naes L, Westfall TC (1987). Preferential stimulation of ventral tegmental area dopaminergic neurons by nicotine. Eur J Pharmacol 141: 395-399.

Mets B, Diaz J, Soo E, Jamdar S (1999). Cocaine, norcocaine, ecgonine methylester and benzoylecgonine pharmacokinetics in the rat. Life Sci 65: 1317-1328.

Nelson AM, Larson GA, Zahniser NR (2009). Low or high cocaine responding rats differ in striatal extracellular dopamine levels and dopamine transporter number. J Pharmacol Exp Ther 331: 985-997.

Nicoll RA, Madison DV (1982). General anesthetics hyperpolarize neurons in the vertebrate central nervous system. Science 217: 1055-1057.

O’Dell LE, Khroyan TV, Neisewander JL (1996). Dose-dependent characterization of the rewarding and stimulant properties of cocaine following intraperitoneal and intravenous administration in rats. Psychopharmacology (Berl) 123: 144-153.

O'Leary ME, Chahine M (2002). Cocaine binds to a common site on open and inactivated human heart $(\mathrm{Na}(\mathrm{v}) 1.5)$ sodium channels. J Physiol 541(Part 3): 701-716.

Pan WH, Lai YJ, Chen NH (1995). Differential effects of chloral hydrate and pentobarbital sodium on a cocaine level and its catecholamine response in the medial prefrontal cortex: a comparison with conscious rats. J Neurochem 64: 2653-2659.

Pederson CL, Wolske M, Peoples LL, West MO (1997). Firing rate dependent effect of cocaine on single neurons of the rat lateral striatum. Brain Res 760: 261-265.

Peoples LL, Gee F, Bibi R, West MO (1998). Phasic firing time locked to cocaine self-infusion and locomotion: dissociable firing patterns of single nucleus accumbens neurons in the rat. J Neurosci 18: 7588-7598.

Peoples LL, West MO (1996). Phasic firing of single neurons in the rat nucleus accumbens correlated with the timing of intravenous cocaine self-administration. J Neurosci 16: 3459-3473.

Piazza PV, Deminiere JM, Le Moal M, Simon H (1989). Factors that predict individual vulnerability to amphetamine self-administration. Science 245: 1511-1513.

Piazza PV, Deminiere JM, Maccari S, Mormede P, Le Moal M, Simon H (1990). Individual reactivity to novelty predicts probability of amphetamine self-administration. Behav Pharmacol 1: 339-345.

Piazza PV, Deroche-Gamonent V, Rouge-Pont F, Le Moal M (2000). Vertical shifts in self-administration dose-response functions predict a drug-vulnerable phenotype predisposed to addiction. J Neurosci 20: 4226-4232.

Pierce RC, Kumaresan V (2006). The mesolimbic dopamine system: the final common pathway for the reinforcing effect of drugs of abuse? Neurosci Biobehav Rev 30: 215-238. 
Pierre PJ, Vezina P (1997). Predisposition to self-administer amphetamine: the contribution of response to novelty and prior exposure to the drug. Psychopharmacology (Berl) 129: 277-284.

Porrino LJ (1993). Functional consequences of acute cocaine treatment depend on route of administration. Psychopharmacology (Berl) 112: 343-351.

Reith ME, Li MY, Yan QS (1997a). Extracellular dopamine, norepinephrine, and serotonin in the ventral tegmental area and nucleus accumbens of freely moving rats during intracerebral dialysis following systemic administration of cocaine and other uptake blockers. Psychopharmacology (Berl) 134: 309-317.

Reith ME, Meisler BE, Sershen H, Lajtha A (1986). Structural requirements for cocaine congeners to interact with dopamine and serotonin uptake sites in mouse brain and to induce stereotyped behavior. Biochem Pharmacol 35: 1123-1129.

Reith ME, Xu C, Chen NH (1997b). Pharmacology and regulation of the neuronal dopamine transporter. Eur J Pharmacol 324: $1-10$.

Richelson E, Pfenning M (1984). Blockade by antidepressants and related compounds of biogenic amine uptake into rat brain synaptosomes: most antidepressants selectively block norepinephrine uptake. Eur J Pharmacol 104: 277-286.

Ritz MC, Cone EJ, Kuhar MJ (1990). Cocaine inhibition of ligand binding at dopamine, norepinephrine and serotonin transporters: a structure-activity study. Life Sci 46: 635-645.

Robinson TE, Berridge KC (2003). Addiction. Annu Rev Psychol 54: $25-53$.

Ross SB, Renyi AL (1967). Inhibition of the uptake of tritiated catecholamines by antidepressant and related agents. Eur J Pharmacol 2: 181-186.

Sabeti J, Gerhardt GA, Zahniser NR (2002). Acute cocaine differentially alters accumbens and striatal dopamine clearance in low and high cocaine locomotor responders: behavioral and electrochemical recordings in freely moving rats. J Pharmacol Exp Ther 302: 1201-1211.

Schilstrom B, Yaka R, Argilli E, Suvarna N, Schumann J, Chen BT et al (2006). Cocaine enhances NMDA receptor-mediated currents in ventral tegmental area cells via dopamine D5 receptor-dependent redistribution of NMDA receptors. $J$ Neurosci 26: 8549-8558.

Shepard PD, German DC (1988). Electrophysiological and pharmacological evidence for the existence of distinct subpopulations of nigrostriatal dopaminergic neuron in the rat. Neuroscience 27: 537-546.

Steffensen SC, Taylor SR, Horton ML, Barber EN, Lyle LT, Stobbs $\mathrm{SH}$ et al (2008). Cocaine disinhibits dopamine neurons in the ventral tegmental area via use-dependent blockade of GABA neuron voltage-sensitive sodium channels. Eur J Neurosci 28: 2028-2040.

Stoffel EC, Cunningham KA (2008). The relationship between the locomotor response to a novel environment and behavioral disinhibition in rats. Drug Alcohol Depend 92: 69-78.

Strichartz G (1976). Molecular mechanisms of nerve block by local anesthetics. Anesthesiology 45: 421-441.

Stuber GD, Wightman RM, Carelli RM (2005). Extinction of cocaine self-administration reveals functionally and temporally distinct dopaminergic signals in the nucleus accumbens. Neuron 46: $661-669$

Swanson LW (1982). The projections of the ventral tegmental area and adjacent regions: a combined fluorescent retrograde tracer and immunofluorescence study in the rat. Brain Res Bull 9: 321-353.

Thierry AM, Tassin JP, Blanc G, Glowinski J (1976). Selective activation of mesocortical DA system by stress. Nature 263: 242-244.

Trulson ME, Trulson VM (1983a). Chloral hydrate anesthesia alters the responsiveness of dorsal raphe neurons to psychoactive drugs. Life Sci 32: 949-956.

Trulson ME, Trulson VM (1983b). Chloral hydrate anesthesia blocks the excitatory response of dorsal raphe neurons to phasic auditory and visual stimuli in cats. Brain Res 265: 129-133.

Ungless MA, Whistler JL, Malenka RC, Bonci A (2001). Single cocaine exposure in vivo induces long-term potentiation in dopamine neurons. Nature 411: 583-587.

Vezina P (2004). Sensitization of midbrain dopamine neuron reactivity and the self-administration of psychomotor stimulant drugs. Neurosci Biobehav Rev 27: 827-839.

Wang RY (1981). Dopaminergic neurons in the rat ventral tegmental area. II. Evidence for autoregulation. Brain Res Rev 3: $141-151$.

Warenycia MW, McKenzie GM (1984). Responses of striatal neurons to anesthetics and analgesics in freely moving rats. Gen Pharmacol 15: 517-522.

Westerink BH, Lejeune B, Korf J, Van Praag HM (1977). On the significance of regional dopamine metabolism in the rat brain for the claksification of centrally acting drugs. Eur J Pharmacol 42: $179-190$.

White FJ (1996). Synaptic regulation of mesocorticolimbic dopamine neurons. Annu Rev Neurosci 19: 405-436.

White FJ, Kalivas PW (1998a). Neuroadaptations involved in amphetamine and cocaine addiction. Drug Alcohol Depend 51: 141-153.

White FJ, Wang RY (1983). Comparison of the effects of LSD and lisuride on A10 dopamine neurons in the rat. Neuropharmacology 22: 669-676.

White FJ, Wang RY (1984a). A10 dopamine neurons: role of autoreceptors in determining firing rate and sensitivity to dopamine agonists. Life Sci 34: 1161-1170.

White FJ, Wang RY (1984b). Pharmacological characterization of dopamine autoreceptors in the rat ventral tegmental area: microiontophoretic studies. J Pharmacol Exp Ther 231: 275-280.

White FJ, Wang RY (1986). Electrophysiological evidence for the existence of both D-1 and D-2 dopamine receptors in the rat nucleus accumbens. J Neurosci 6: 274-280.

White IM, Doubles L, Rebec GV (1998b). Cocaine-induced activation of striatal neurons during focused stereotypy in rats. Brain Res 810: 146-152.

Windels F, Kiyatkin EA (2006). General anesthesia as a factor affecting impulse activity and neuronal responses to putative neurotransmitters. Brain Res 1086: 104-116.

Wise RA, Bozarth MA (1984). Brain reward circuitry: four circuit elements 'wired' in apparent series. Brain Res Bull 12: 203-208.

Supplementary Information accompanies the paper on the Neuropsychopharmacology website (http://www.nature.com/npp) 